\title{
Credibility models with dependence induced by common effects and their applications in bank branch performance prediction.
}

\begin{abstract}
One of the important issues in banking affairs is to predict performance of bank branches. While we know some of the factors that influence predicted performance, some unobservable factors called 'error' or 'latent and unobservable variables' in statistics, always exert some effect on prediction. In this paper, for the first time in studies on prediction of performance of bank branches, we use credibility theory to model the effects of unobservable factors induced by 'common effects'. The models are then used to predict expected performance for a number of branches given the history of all observable performances. We give illustrative example to demonstrate the ideas.
\end{abstract}

Keyword: Credibility models; Common effects; Performance prediction; Business development. 